DOI https://doi.org/10.18551/rjoas.2017-11.19

\title{
SALES PROMOTION AND PRICE IMPACT ON PURCHASING DECISION OF XIAOMI SMARTPHONE TO CONSUMERS IN WEST JAKARTA
}

\author{
Firman Chandra Raharja, Rahardjo Mukti \\ Faculty of Economics, Tarumanagara University, Jakarta \\ *E-mail: sln.chan0706@gmail.com
}

\begin{abstract}
This research aimed: 1) to find out any sales promotion impact on purchasing decision of Xiaomi Smartphone to consumers in West Jakarta?, 2) to find out any price impact on purchasing decision of Xiaomi Smartphone to consumers in West Jakarta?, 3) to find out any sales promotion and price impact on purchasing decision of Xiaomi Smartphone to consumers in West Jakarta? The population was all consumers in West Jakarta. The sample of the research was limited to 100 consumers in West Jakarta. The purposive sampling method was used in this research. The data collection method was conducted by distributing questionnaires to 100 respondents. The data analysis technique was the multiple regression analysis with non-probability sampling. The findings of the research showed four results. First, sales promotion had a partially significant impact on purchasing decision with $95 \%$ probability level. Second, price had a partially significant impact on purchasing decision with $95 \%$ probability level. Finally, sales promotion and price had a simultaneously significant impact on purchasing decision with $95 \%$ probability level.
\end{abstract}

\section{KEY WORDS}

Promotion, sales, purchasing decision, consumer.

Technological developments have added colors to various kinds of competition in all fields. One of them is telecommunication field. The development of telecommunication field has grown fast with the continuous growing number of mobile phone products in which initially mobile phones serve as a means of wireless communication; then it turns into a tool that is functionally in today's modern era; it is called smartphones (Berger, 2015). There are many smartphone companies competing to create popular smartphone products; one of them is Xiaomi Inc., (Liu, Liu, and Zheng, 2016). Xiaomi Inc. initially launched the smartphone in 2011. Xiaomi can bring the same features as Apple and Samsung have but with a much cheaper price. Smartphone business competition is increasingly competitive which requires companies to be able providing and delivering clear and distinct information, better than its competitors, so that the company can attract attention and purchase from the consumers. One way could be done by companies in attracting consumers is by having marketing activities (Cecere et al, 2015).

Marketing activity has several interconnected components; such as product, price, distribution and promotion. Promotion becomes one of the best strategies in delivering information to the consumer. Sales promotion takes an important role in influencing purchasing decisions. Sales promotion is a direct inducement that offers incentives or more values of a product to the consumer. Sales promotion includes a wide variety of promotional tools designed to stimulate faster or stronger market responses (Albaum and Tse, 2001). According to Chandon et al. (2000), sales promotion is a marketing communications activity; other than advertisement, personal sales, and public relations, where short-term incentives motivate consumers and channel members to immediately purchase goods or services; both by having low prices or by raising the added value.

In addition to sales promotion, price also plays an important role in making purchasing decisions. Nowadays, with the lower purchasing power of the majority of consumers, pricing is very important as consumers are increasingly critical and selective in spending money (Puccinelli et al, 2009). According to Tantry et al. (2013), defining price is everything done by consumers to get the benefits offered by the various marketing of the company. Sales 
promotion is a short-term incentive in promotional activities to stimulate the purchase of a product in a variety of ways; such as trade shows, sales incentives, coupons and other (Ngai, et al, 2009). According to Achrol and Kotler, (1999) sales promotion is a key element in marketing campaigns. Sales promotion consists of a collection of various-mostly shortterm-incentive tools designed to encourage the purchase of a particular product or service more quickly or greater by the consumer or merchant.

Purchasing decision of a product begins with the consumer's awareness of the problem in their needs. Consumers are aware that there is a difference between the actual and the desired conditions. The result is that the consumers will seek more information to find out which product they are interested in, (Comegys et al, 2006). Purchasing decision is an integration process that combines knowledge to evaluate two or more alternative behaviors and choose one of them, (Chen et al, 2009).

This research aimed: 1 ) to find out any sales promotion impact on purchasing decision of Xiaomi Smartphone to consumers in West Jakarta?, 2) to find out any price impact on purchasing decision of Xiaomi Smartphone to consumers in West Jakarta?, 3) to find out any sales promotion and price impact on purchasing decision of Xiaomi Smartphone to consumers in West Jakarta?

\section{METHODS OF RESEARCH}

One step to be considered in the implementation of a research is to determine the population of the research in which will be conducted. The population of the research was all consumers in West Jakarta who had not owned or had already owned Xiaomi smartphone. The sampling method used was non-probability sampling; it means that the sampling technique did not use the procedure of opportunity selection but rather rely on personal judgment of the researcher, (Tansey, 2007). In the research questionnaire, samples were collected and the sample total was in accordance with the rules of primary data collection. According to Wagner et al. (2007) stated that generally social research such as economics, sociology, psychology, management, banking, and marketing, obtaining primary data with samples $(n>30)$. Based on the reference, then the number of samples were as many as 100 respondents.

Data collection method used in this research was by using questionnaire. Questionnaire is a data collection technique that is conducted by distributing a set of questions or written statement to be answered by the respondents. Questionnaire is an efficient data collection technique if researchers know with certainty the variables to be measured and know what cannot be expected from the respondents. Questionnaire, as a data collection technique, is perfect for collecting large amounts of data (Hammersley, 2003).

\section{RESULTS AND DISCUSSION}

Classical Assumption Test. Before performing data analysis, to find out any sales promotion and price impact on purchasing decision of Xiaomi Smartphone to consumers in West Jakarta, classical assumption test was firstly done; including normality test, multicollinearity, autocorrelation and heteroscedasticity. Due to the data type of cross section of this research, the classical assumption testing then had only three types of normality test, multicollinearity and heteroscedasticity.

Normality Test. In this research, the normality test was performed by looking at the spread of data or by looking at the direction of data that follows or does not follow the normal line (Normal Probability P - P Plot) through the SPSS data processing. 


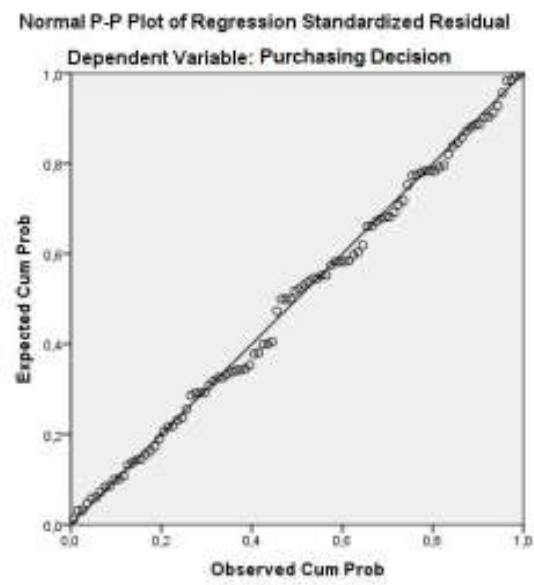

Figure 1 - Normality Test

Based on the information on the figure above, the points are around the line and follow the direction of diagonal line or histogram graph so that it can be concluded that the data is normally distributed.

Multicollinearity Test. The existence of multicollinearity was identified by the value of VIF (Variance Inflation Factor). If the VIF value is less than 10, then the regression model does not have multicollinearity and if the VIF value is more than 10 then the regression model has multicollinearity.

Table 1 - Multicollinearity Test

\begin{tabular}{|c|c|c|}
\hline \multirow{2}{*}{ Model } & \multicolumn{2}{|c|}{ Collinearity Statistics } \\
\cline { 2 - 3 } & Tolerance & VIF \\
\hline Sales Promotion & 0.492 & 2.033 \\
Price & 0.492 & 2.033 \\
\hline
\end{tabular}

Based on the table, all variables have VIF values smaller than 10 , therefore it can be concluded that the regression model has no multicollinearity.

Heteroscedasticity Test. Heteroscedasticity test aims to test the occurrence of variance inequality from one residual to another observation in this regression model. An appropriate regression model has no heteroscedasticity. Heteroscedasticity test can be performed by using scatter plot. If there is a certain pattern, such as points that form a regular pattern, then it indicates that there is no heteroscedasticity occurs. If there is no clear pattern and the points spread above and below 0 on the $Y$ axis, then heteroscedasticity does not occur. The picture below will illustrate the scatter plot:

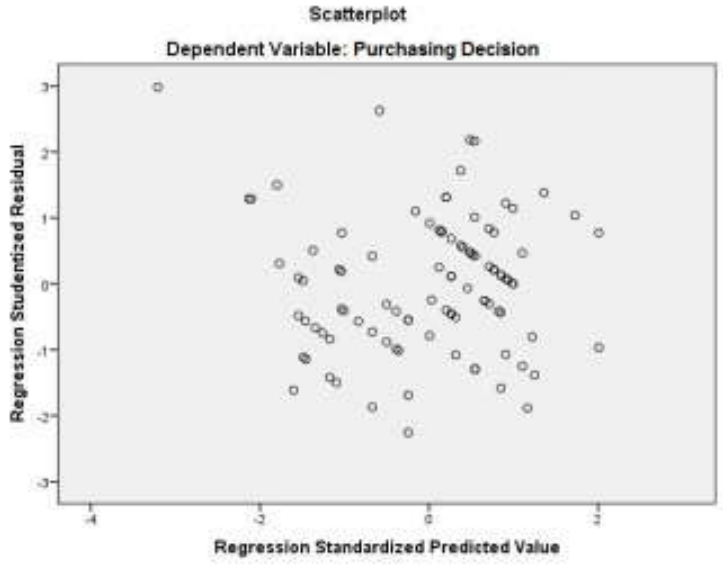

Figure 2 - Scatter Plot 
Based on the picture, it can be seen that all spots spread and there is no clear pattern so it can be concluded that there is no heteroscedasticity in regression model. From the analysis of classical assumption test, it can be concluded that the regression analysis is performed well and multiple regression model can be used to analyze the data because it meets the requirements:

1) There is normality;

2) There is no multicollinearity;

3) There is no heteroscedasticity.

Multiple Regression Analysis. Multiple regression analysis is used to determine the effect of independent variable $(X)$ on the change of dependent variable $(Y)$. In this research, the independent variables are communication of sales promotion $\left(X_{1}\right)$ and price $\left(X_{2}\right)$. Dependent variable in this research is purchasing decision $(\mathrm{Y})$. Below is the SPSS output to form a regression equation:

Table 2 - Analysis Table of Multiple Regressions

\begin{tabular}{|c|c|c|c|}
\hline \multirow{2}{*}{ Model } & \multicolumn{2}{|c|}{ Unstandardized Coefficients } & \multirow{2}{*}{ Standardized Coefficients Beta } \\
\cline { 2 - 3 } & B & Std. Error & \\
(Constant) & 1.173 & 1.063 & 0.368 \\
Sales Promotion & 0.184 & 0.053 & 0.371 \\
Price & 0.232 & 0.066 & \\
\hline
\end{tabular}

Based on the table above, the regression equation can be formulated, namely: Purchasing Decision $=1.173+0.184$ of sales promotion +0.232 of price. The following is the explanation of the above equation:

- If there is no sales promotion and price $(X 1$ and $X 2=0)$ then the purchasing decision is 1,173

- If sales promotion increases and price is considered as constant, then the purchasing decision will increase by 0.184

- If the price increases and sales promotion is considered as constant, then the purchasing decision will increase by 0.232

Hypothesis Testing. In this research, hypothesis should be tested first to answer the formulation of research problems on any sales promotion and price impact on purchasing decision. In performing data processing, the researcher used SPSS program for windows version 20. Hypothesis testing of this research was performed simultaneously or partially. The purpose of simultaneously testing was to see the impact of all independent variables to the dependent variable. Meanwhile, the partial testing aimed to see the impact of each independent variable to the dependent variable.

F - Test (Simultaneously Hypothesis Testing). As discussed in Chapter III, F - Test is basically showing whether all independent variables can be included into the regression equation model which has a simultaneous influence on the dependent variable (simultaneous testing). The $\mathrm{F}$ - Test (ANOVA) is presented in the following table:

Table 3 - Coefficient Test of Double Regressions simultaneously with F - Test

ANOVAa

\begin{tabular}{|ll|c|c|c|c|c|}
\hline \multicolumn{1}{|c|}{ Model } & Sum of Squares & df & Mean Square & F & Sig. \\
\hline \multirow{2}{*}{1} & Regression & 266.733 & 2 & 133.366 & & \\
& Residual & 302.577 & 97 & 3.119 & & \\
& Total & 569.310 & 99 & & & \\
\hline
\end{tabular}

Based on the table, the level of significance is 0.000 in which the number has a smaller value than the value of $\alpha$ that is equal to 0.05 . Therefore, it can be concluded that $\mathrm{H}_{0}$ is rejected; and it means that at least there is one independent variable that can affect purchasing decision by $95 \%$ of confidence level. Thus, in answering the research hypothesis, partial testing (t-test) can be done to know which independent variable affect the dependent variable. 
$T-$ Test (Partial Hypothesis Testing). T-test hypothesis testing is performed to find out how far the impact of one independent variable in explaining the variation of dependent variable individually. Partial test results on the regression coefficient can be seen in the following table:

Table 4 - T - Test Table

\begin{tabular}{|c|c|c|c|c|c|}
\hline \multirow{2}{*}{ Model } & \multicolumn{2}{|c|}{ Unstandardized Coefficients } & Standardized Coefficients & \multirow{2}{*}{ Sig. } \\
\cline { 2 - 4 } & $\mathrm{B}$ & Std. Error & Beta & 3.489 & .001 \\
Sales promotion & 0.184 & 0.053 & 0.368 & 3.519 & .001 \\
\hline Price & 0.232 & 0.066 & 0.371 & \\
\hline
\end{tabular}

Hypothesis Testing Against Regression Coefficient ( $\beta_{1}$ Test). Based on the table, by having significance value with $\alpha$ value of 0.05 , the result is 0.001 . It indicates that sales promotion variable has smaller significance value than $\alpha$ value which means that $H_{0}$ is rejected; it can be concluded that there is significant impact between sales promotion variable to purchasing decision variable $(\mathrm{Y})$ if price variable is considered as constant with the level of confidence of $95 \%$.

Hypothesis Testing Against Regression Coefficients ( $\beta_{2}$ Test). Based on the table, by having significance value with $\alpha$ value of 0.05 , the result is 0.001 . It indicates that price variable has smaller significance value than $\alpha$ value which means that $\mathrm{H}_{0}$ is rejected; it can be concluded that there is significant impact between price variable to purchasing decision variable $(\mathrm{Y})$ if sales promotion variable is considered as constant with the level of confidence of $95 \%$.

Determination Test $\left(R^{2}\right)$. Determination test $\left(R^{2}\right)$ is performed to know the proportion ability of independent variables in explaining the variation of dependent variable. The following is the calculation of the determination test (R2); it is shown in the following table:

Table 5 - Testing R. Square

\section{Summary ${ }^{\mathrm{b}}$ Model}

\begin{tabular}{|c|c|c|c|c|}
\hline Model & $\mathrm{R}$ & R Square & Adjusted R Square & Std. Error of the Estimate \\
\hline 1 & $.684^{\mathrm{a}}$ & .469 & .458 & 1.76617 \\
\hline
\end{tabular}

Based on the table, the R-square value is 0.469 which means that it is equal to $46.9 \%$; dependent variable (purchasing decision) can be explained by independent variables (sales promotion and price) and the rest of $53.1 \%$ can be explained by other variables.

\section{DISCUSSION OF RESULTS}

In this research, the results of validity and reliability analysis indicate that all variables are valid and reliable. In other words, they are valid because all items of the statement have corrected item-total correlation value greater than 0.2 (Aritonang, 2007) and they are reliable because the Cronbach's Alpha value is greater than 0.7 (Aritonang, 2007). It indicates that all the instruments of the statement in the questionnaire, as a measurement tool in this research, are feasible to be used and preceded to the next analysis.

According to the description of the research subjects, it is noted that the characteristics of the respondents are in terms of gender, age, price range of smartphones and smartphone turnover intensity. Classical assumptions testing on regression analysis shows that multiple regression models are appropriate to be used in data analyzing. Because it has met the requirement that there is normality, there is no multicollinearity and heteroscedasticity. Results of multiple regression analysis, to determine the impact of sales promotion and prices on purchasing decision, resulted the equation: purchasing decision $=1.173+0.184$ of sales promotion +0.232 of price. 
The results of simultaneous hypothesis testing ( $\mathrm{F}$ - Test) showed that the significance value of 0.000 is smaller than the value of $\alpha 0.05$. So it can be concluded that there is at least one independent variable that affects the dependent variable with a confidence level of $95 \%$. The result of partial hypothesis testing ( $\mathrm{t}$ - Test) shows that sales promotion and price variable had impacts purchasing decision. Based on the conclusions of multiple regression analysis results, it can be reflected that the considerations leading to a positive purchasing decision are sales promotion and price. From the above analysis, it can be seen that the Rsquare value is 0.469 ; it means that $46.9 \%$ of the dependent variable (purchasing decision) can be explained by independent variables (sales promotion and sales) and the rest of $53.1 \%(100 \% 46.9 \%)$ can be explained by other variables that are not included in this research.

\section{CONCLUSION AND SUGGESTIONS}

Based on the research and discussion that have been conducted, the following conclusions can be drawn:

There is an impact of sales promotion on the purchasing decision by comparing significance value with $\alpha$ value of 0.05 ; the obtained result is equal to 0,001 (less than 0.05 ) and its impact is equal to 0,184 at regression equation.

There is an impact of price on the purchasing decision by comparing significance value with a value of 0.05 ; the obtained result is equal to 0,001 (less than 0.05 ) and its impact is equal to 0,232 at regression equation.

There is an impact of sales promotion and price on the purchasing decision; the level of significance is 0.000 in which the number has a smaller value than a value of 0.05 . The results of regression are: purchasing decision $=1.173+0.184$ of sales promotion +0.232 of price.

Based on the result of the research, the researcher will provide some useful suggestions practically and theoretically, as follows:

Practically, the researcher suggested that the company minimize the production cost of Xiaomi smartphone so that the price of Xiaomi smartphone will be cheaper because in this research the most influential variable is the price, in purchasing decision of Xiaomi smartphone. In addition to price, the company should also pay attention to other factors that influence purchasing decisions such as sales promotion.

Theoretically, in order to sharpen the important findings of further research, related to purchasing decisions, it is advisable to add other independent variables that may influence purchasing decisions such as product quality, advertising and other factors.

\section{REFERENCES}

1. Berger, A. A. (2015). Media and communication research methods: An introduction to qualitative and quantitative approaches. Sage Publications.

2. Liu, D., Liu, H., \& Zheng, S. (2016). U.S. Patent No. D749,534. Washington, DC: U.S. Patent and Trademark Office.

3. Cecere, G., Corrocher, N., \& Battaglia, R. D. (2015). Innovation and competition in the smartphone industry: Is there a dominant design?. Telecommunications Policy, 39(3), 162-175.

4. Albaum, G., \& Tse, D. K. (2001). Adaptation of international marketing strategy components, competitive advantage, and firm performance: a study of Hong Kong exporters. Journal of international marketing, 9(4), 59-81.

5. Chandon, P., Wansink, B., \& Laurent, G. (2000). A benefit congruency framework of sales promotion effectiveness. Journal of marketing, 64(4), 65-81.

6. Puccinelli, N. M., Goodstein, R. C., Grewal, D., Price, R., Raghubir, P., \& Stewart, D. (2009). Customer experience management in retailing: understanding the buying process. Journal of retailing, 85(1), 15-30. 
7. Tantry, U. S., Bonello, L., Aradi, D., Price, M. J., Jeong, Y. H., Angiolillo, D. J., ... \& Kirtane, A. (2013). Consensus and update on the definition of on-treatment platelet reactivity to adenosine diphosphate associated with ischemia and bleeding. Journal of the American College of Cardiology, 62(24), 2261-2273.

8. Ngai, E. W., Xiu, L., \& Chau, D. C. (2009). Application of data mining techniques in customer relationship management: A literature review and classification. Expert systems with applications, 36(2), 2592-2602.

9. Achrol, R. S., \& Kotler, P. (1999). Marketing in the network economy. The Journal of Marketing, 146-163.

10. Comegys, C., Hannula, M., \& Väisänen, J. (2006). Longitudinal comparison of Finnish and US online shopping behaviour among university students: The five-stage buying decision process. Journal of Targeting, Measurement and Analysis for Marketing, 14(4), 336-356.

11. Chen, Y. C., Shang, R. A., \& Kao, C. Y. (2009). The effects of information overload on consumers' subjective state towards buying decision in the internet shopping environment. Electronic Commerce Research and Applications, 8(1), 48-58.

12. Tansey, O. (2007). Process tracing and elite interviewing: a case for non-probability sampling. PS: Political Science \& Politics, 40(4), 765-772.

13. Wagner, G. G., Frick, J. R., \& Schupp, J. (2007). The German Socio-Economic Panel study (SOEP)-evolution, scope and enhancements.

14. Hammersley, M. (2003). Dilemma Qualitative Method. Routledge. 